\title{
Transcriptome analysis of alternative splicing in peanut (Arachis hypogaea L.)
}

Jian Ruan ${ }^{1}$, Feng Guo ${ }^{2}$, Yingying Wang ${ }^{2}$, Xinguo $\mathrm{Li}^{2}$, Shubo Wan ${ }^{1,2^{*}}$, Lei Shan ${ }^{1,2^{*}}$ and Zhenying Peng ${ }^{1,2^{*}}$

\begin{abstract}
s
Background: Alternative splicing (AS) represents a mechanism widely used by eukaryotes for the posttranscriptional regulation of genes. The detailed exploration of AS in peanut has not been documented.

Results: The strand-specific RNA-Seq technique was exploited to characterize the distribution of AS in the four samples of peanut (FH1-seed1, FH1-seed2, FH1-root and FH1-leaf). AS was detected as affecting around 37.2\% of the full set of multi-exon genes. Some of these genes experienced AS throughout the plant, while in the case of others, the effect was organ-specific. Overall, AS was more frequent in the seed than in either the root or leaf. The predominant form of AS was intron retention, and AS in transcription start site and transcription terminal site were commonly identified in all the four samples. It is interesting that in genes affected by AS, the majority experienced only a single type of event. Not all of the in silico predicted transcripts appeared to be translated, implying that these are either degraded or sequestered away from the translation machinery. With respect to genes involved in fatty acid metabolism, about $61.6 \%$ were shown to experience AS.
\end{abstract}

Conclusion: Our report contributes significantly in AS analysis of peanut genes in general, and these results have not been mentioned before. The specific functions of different AS forms need further investigation.

Keywords: Arachis hypogaea L., Alternative splicing, Transcriptome analysis, Organ-specific expression, Fatty acid metabolism

\section{Background}

In eukaryotes, AS, a process in which more than one transcript is produced from a single coding sequence, has evolved as a ubiquitous mode of post-transcriptional gene regulation $[1,2]$. Defective AS has been associated with a number of clinical conditions [3, 4], genetic diseases [5-7] and aging [8]. In plants, AS has been shown to regulate growth, development, signal transduction, flowering, circadian clock function and the response to various environmental cues [9-13], as well as being associated with speciation [14-16]. Five forms of AS have been recognized, namely transcription start site (TSS), transcription terminal site (TTS), exon skipping (ES), intron retention (IR), alternative exon ends $\left(5^{\prime}, 3^{\prime}\right.$, or both; AE) [17].

High throughput sequencing data sets provide a major opportunity for investigating the genome-wide distribution

\footnotetext{
* Correspondence: wansb@saas.ac.cn; shlei1025@163.com; pengzhenying2005@126.com

${ }^{1}$ College of Life Science, Shandong University, Jinan, China

Full list of author information is available at the end of the article
}

of AS. The impression to date is that the extent of AS increases with both organ and species complexity $[18,19]$. In animal genomes the proportion of genes harboring intron(s) which experience AS lies in the range 20-95\% [20-24], while the equivalent proportion in plant genomes is variable greatly [25-33]. In both animals and yeast, ES is the most prevalent form of AS, while IR is the least common [22, 24, 34, 35]. In contrast, in plants, most AS events involve IR, with the relative frequency of the five forms of AS differing across the monocotyledonous/dicotyledonous divide [25, 36-38]. Approximately $60-75 \%$ of AS events result in changes to the binding property, phosphorylation status, stability, intracellular localization, enzymatic activity or signaling activity of the gene product [1,38-40]. Many AS-generated foreshortened transcripts are processed by nonsense-mediated decay or are regulated by microRNAs (miRNAs) [41-44]. At least 13\% of intron-containing genes in Arabidopsis thaliana are potentially regulated by nonsense-mediated decay [45].

The peanut (Arachis hypogaea L.), a leading oil and protein crop, is an allotetraploid $(2 n=4 \times=40)$ developed 
from a hybrid between the two diploid wild species $A$. duranensis and A. ipaensis. Sequencing of these two progenitor species has generated coverage of about $96 \%$ of the cultivated peanut genome [46], thereby providing a firm basis for genetic investigations. As yet, the genome-wide occurrence of AS in peanut has not been explored. Here, the strand-specific RNA-Seq approach has been used to characterize the occurrence of AS in two distinct developmental stages of the seed, and in the seedling root and leaf of a leading peanut cultivar.

\section{Results}

\section{Sequencing of the four organ-provenance libraries from peanut}

Four samples (FH1-seed1, FH1-seed2, FH1-root and FH1-leaf) from peanut have been prepared for strand-specific RNA-Seq. The RNA-Seq platform realized $51.3 \times 10^{9}$ bases, for which the Q30 value was > $88.90 \%$ and the range in GC content $44.48-50.48 \%$ (Additional file 1: Table S1). After editing, the remaining high quality sequence was represented by $27.25 \times 10^{9}$ bases in FH1-seed1 and FH1-seed2 combined, $12.42 \times$ $10^{9}$ bases in FH1-root and $11.67 \times 10^{9}$ bases in FH1-leaf. The raw sequence data have been submitted to the NCBI BioProject database under accession number PRJNA354652. When the clean reads were aligned with the genomic sequences of $A$. duranensis and A. ipaensis, the matching ratio ranged from 79.91 to $87.49 \%$ (Additional file 2: Table S2); the highest ratio was associated with the FH1-leaf library, but the number of unique mapped reads was the lowest in this library. In all four libraries, the reads mapped more frequently to the ' + rather than to the '-' strand.

\section{The peanut transcriptome}

The total 431,596 unique transcripts were pieced together in the four samples, 107,102 from FH1-seed1, 110,005 from FH1-seed2, 109,210 from FH1-root, and 105,279 from FH1-leaf, respectively (Table 1). Transcripts were detected for 54,047 genes (Table 2), which represents $68.8 \%$ of combined number of genes present in the two wild progenitors [47]. Following the application of fragments per kilobase of exon per million fragments mapped (FPKM) threshold of 0.1, the number of genes detected was reduced to 48,236 (Table 2). These genes broke down into 40,679 from FH1-seed1, 40,442 from FH1-seed2, 41,780 from FH1-root and 40,939 from FH1-leaf. The transcription of 34,427 of these genes was detected in all four libraries, leaving 1202 specific to FH1-seed1, 710 to FH1-seed2, 2055 to FH1-root and 1461 to FH1-leaf (Fig. 1a).

\section{AS in the peanut transcriptome}

Applying the FPKM threshold of 0.1 to the set of 48,236 transcribed genes revealed 27,829 genes as showing evidence of AS (Table 2): this figure represents $57.69 \%$ of the transcriptome and $37.2 \%$ of the full set of multi-exon genes predicted from the genome sequence. The four libraries harbored, respectively, 20,213 (FH1-seed1), 19,534 (FH1-seed2), 19,326 (FH1-root) and 19,259 (FH1-leaf) genes affected by AS. A total of 12,317 of the AS genes was represented in all four of the libraries, while the number of library-specific AS genes was, respectively, 1697, 1345, 1742 and 1616 (Fig. 1b). A total of 4318 genes were confined to the two libraries prepared from developing seed. AS events were overall more frequent in the seed than in the root or leaf (Table 3), and the number of splicing isoforms detected in seed was also more than that in root and leaf (Additional file 3: Table S3), implying a particular importance for AS in seed development.

The number of AS events detected in FH1-seed1 was 92,483, in FH1-seed2 85,562, in FH1-root 79,763 and in FH1-leaf 83,290 (Table 3). According to [17], five distinct types of AS event can be recognized, namely TSS, TTS, ES, IR, and AE (Table 2). The most frequent AS event observed in peanut (26.84-33.45\%) involved IR, and the least frequent (11.68-14.17\%) involved ES. $\mathrm{AE}$ events accounted for, respectively, 20.06-22.07\%. These estimates agree with previous studies in other plants. TSS and TTS events accounted for, respectively, $19.01-20.78 \%$ and $15.70-17.25 \%$ respectively.

TSS and TTS events were commonly identified in the four samples. Within the set of FH1-seed, 17,584 TSS events affected 14,314 genes, 14,523 TTS events affected 12,680 genes, the number of TSS and TTS events generated per gene is 1.22 and 1.15 respectively (Table 4). Within the four samples, the number of TSS and TTS events generated per gene is $1.18-1.22$ and $1.12-1.15$ respectively (Table 4), the number of TSS events generated per gene is more than that of TTS events.

Table 1 Statistics of the number of the expressed genes and transcripts in the four samples from different peanut organs

\begin{tabular}{llll}
\hline Sample ID & Number of transcripts (with FPKM $\geq 0.1$ ) & Expressed Genes (with FPKM $\geq 0.1$ ) & Average number of transcripts per gene \\
\hline FH1-seed1 & 107,102 & 40,679 & 2.63 \\
FH1-seed2 & 110,005 & 40,442 & 2.72 \\
FH1-root & 109,210 & 41,780 & 2.61 \\
FH1-leaf & 105,279 & 40,939 & 2.57 \\
\hline
\end{tabular}


Table 2 Statistics of the number of expressed genes and AS genes in the four samples from different peanut organs

\begin{tabular}{lllll}
\hline Sample ID & $\begin{array}{l}\text { Total detected genes } \\
\text { (with count number } \geq 1)\end{array}$ & $\begin{array}{l}\text { Expressed Genes } \\
\text { (with FPKM } \geq 0.1 \text { ) }\end{array}$ & $\begin{array}{l}\text { AS genes } \\
\text { (with FPKM } \geq 0.1)\end{array}$ & $\begin{array}{l}\text { AS genes / Expressed } \\
\text { genes (\%) }\end{array}$ \\
\hline FH1-seed1 & 49,298 & 40,679 & 20,213 & $49.69 \%$ \\
FH1-seed2 & 46,343 & 40,442 & 19,534 & $48.30 \%$ \\
FH1-root & 46,982 & 41,780 & 19,326 & $46.26 \%$ \\
FH1-leaf & 48,548 & 40,939 & 19,259 & $47.04 \%$ \\
Total & 54,047 & 48,236 & 27,829 & $57.69 \%$ \\
\hline
\end{tabular}

An ES 'event' was defined as a pairing between 'ON' and 'OFF', occurring at the same exon and with the same flanking introns. The same exon or intron may be involved in multiple exon skipping (MSKIP) events, so the estimated number of ES events is more than its real number. Among the ES events, there was a higher number of SKIP_OFF than SKIP_ON events (Table 5). An IR 'event' was also defined as a pairing (IR_ON, IR_OFF). It is interesting that the number of IR_ON events were more than that of IR_OFF ones (Table 6).

Within the set of FH1-seed AS genes, 10,891 ES events affected 4894 genes, 30,931 IR events affected 8468 genes and 18,554 AE events affected 7583 genes (Table 2, Fig. 2a). The number of genes affected exclusively by ES, IR and AE was, respectively, 1984, 3961 and 3180. Thus, altogether, 9125 (63.55\%) genes experienced only a single AS type, 3879 (27.02\%) genes experienced two AS types, while only 1354 (9.43\%) experienced three types. And also, the AS genes experienced simultaneously IR \& AE were more than that experienced simultaneously IR \& ES, and AE \& ES. The transcriptomes represented in the other three libraries displayed a similar distribution of AS events (Fig. 2b-d). Overall, in genes affected by AS, the majority experienced only a single type of event.
Most of the AS genes produced a predominant transcript with a considerable higher level of expression which was detected in all four libraries, along with additional ones occurring at a substantially lower frequency (Additional file 4: Table S4). For example, Aradu.000JC generated four transcripts, two of which were detected in all four libraries, one in FH1-seed1 and FH1-seed2 (but not in either FH1-root or FH1-leaf), and the fourth in FH1-root and FH1-leaf (but not in either FH1-seed1 or FH1-seed2). In a second example, Araip.GAW68 generated 20 transcripts, five of which were represented in all four libraries, only one represented in three libraries, seven ones appeared in two libraries, and seven ones appeared in one library.

\section{Statistical analysis of the exon number of the peanut AS gene}

Cultivated peanut contain two subgenomes (A and B). Although the genome sequencing of cultivated peanut has not been completed, the genome sequencing of two progenitor species of peanut $(A$. duranensis and $A$. ipaensis) has been finished, which contain 78,574 genes (36,734 and 41,840 genes, respectively) [46]. So we use the two wild peanut genomes as reference to analyze our transcriptome data. We analyzed the exon number of

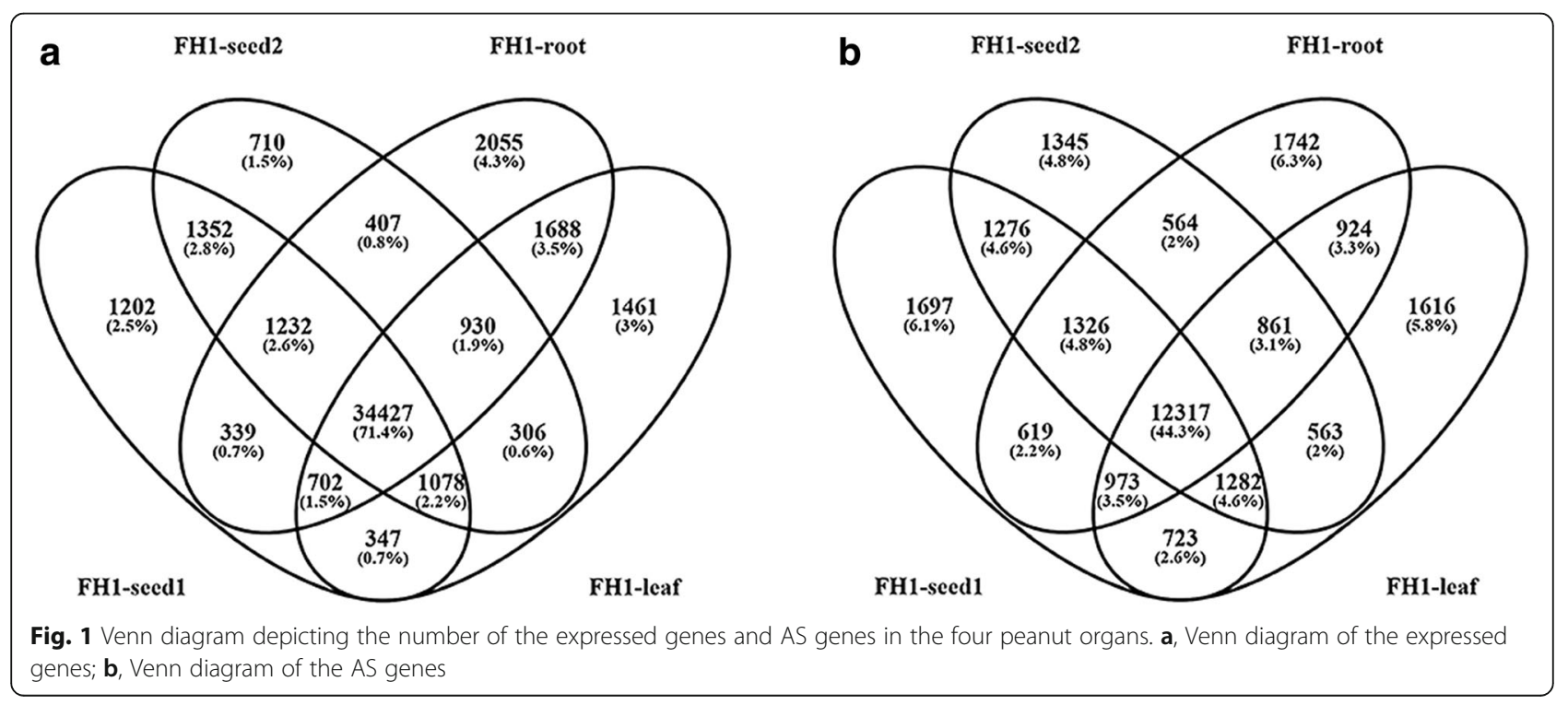


Table 3 Statistics of the number of AS events and AS types in the four samples from different peanut organs

\begin{tabular}{|c|c|c|c|c|c|c|c|c|}
\hline \multirow{2}{*}{$\begin{array}{l}\text { AS } \\
\text { types }\end{array}$} & \multicolumn{2}{|l|}{ FH1-seed1 } & \multicolumn{2}{|l|}{ FH1-seed2 } & \multicolumn{2}{|l|}{ FH1-root } & \multicolumn{2}{|l|}{ FH1-leaf } \\
\hline & AS Events & $\overline{\text { Percentage }}$ & AS Events & $\overline{\text { Percentage }}$ & AS Events & $\overline{\text { Percentage }}$ & AS Events & Percentage \\
\hline TSS & 17,584 & $19.01 \%$ & 16,980 & $19.85 \%$ & 16,572 & $20.78 \%$ & 16,632 & $19.97 \%$ \\
\hline TTS & 14,523 & $15.70 \%$ & 13,657 & $15.96 \%$ & 13,758 & $17.25 \%$ & 13,717 & $16.47 \%$ \\
\hline ES & 10,891 & $11.78 \%$ & 12,124 & $14.17 \%$ & 10,423 & $13.07 \%$ & 9726 & $11.68 \%$ \\
\hline IR & 30,931 & $33.45 \%$ & 24,788 & $28.97 \%$ & 21,408 & $26.84 \%$ & 25,865 & $31.05 \%$ \\
\hline$A E$ & 18,554 & $20.06 \%$ & 18,013 & $21.05 \%$ & 17,602 & $22.07 \%$ & 17,350 & $20.83 \%$ \\
\hline Total & 92,483 & $100.00 \%$ & 85,562 & $100.00 \%$ & 79,763 & $100.00 \%$ & 83,290 & $100.00 \%$ \\
\hline
\end{tabular}

78,574 genes (Fig. 3), and found that the number of intron-less genes were 3740 , accounting for $4.76 \%$ of all genes; the number of genes containing 2 or more exons accounted for about $95 \%$ of the total genes. $47.26 \%$ genes contain $\geq 5$ exons and $15.56 \%$ genes contain $\geq 10$ exons. We analyzed exon number of 27,829 AS genes (Fig. 3). Results showed that the exon number of AS genes distributed mainly from 3 to 10, which accounted for $67.33 \%$ of all AS genes. And that, the occurrence rate of AS genes increased along with the exon number increasing. This was consistency with other reports [48].

\section{GO annotation and GO classification analysis of the peanut AS genes}

We conducted the gene function annotation to several different databases, such as NCBI non-redundant protein sequences $(\mathrm{Nr})$, Clusters of Orthologous Groups of proteins (KOG/COG), Kyoto Encyclopedia of Genes and Genomes (KEGG) and Gene Ontology (GO). Here we analyzed in detail the GO annotation and GO classification of the peanut AS genes. The 27,829 AS genes were subjected to GO classification, resulting in 21,499 being assigned to a GO category (Fig. 4). In the "cellular component" category, the genes were concentrated within the groups "cell part" (22.3\%), "cell" (22.1\%) and "organelle" (19.4\%). In the "molecular function" category, the predominant groups were "binding" (38.9\%) and "catalytic activity" (42.5\%); finally, in the "biological

Table 4 Statistics of the number of TSS and TTS events occurred in the four samples of peanut different organs

\begin{tabular}{lllll}
\hline & Sample ID & AS events & AS genes & Events/gene \\
\hline TSS & FH1-seed1 & 17,584 & 14,431 & 1.22 \\
& FH1-seed2 & 16,980 & 14,250 & 1.19 \\
& FH1-root & 16,572 & 14,071 & 1.18 \\
& FH1-leaf & 16,632 & 13,829 & 1.20 \\
TTS & FH1-seed1 & 14,523 & 12,680 & 1.15 \\
& FH1-seed2 & 13,657 & 12,142 & 1.12 \\
& FH1-root & 13,758 & 12,338 & 1.12 \\
& FH1-leaf & 13,717 & 12,036 & 1.14 \\
\hline
\end{tabular}

process" category, the genes were distributed quite uniformly between the various groups, with the exception of the under-represented "cell killing process" group. The implication was that AS must be important for the regulation of a wide range of biological processes.

\section{New genes identification and optimization of the gene structures}

Most of the sequences were represented in one or both of the progenitor genomes, while 1776 new genes were not (Additional file 5: Table S5); of these, 1250 were able to be functionally assigned by reference to the various sequence databases (Additional file 5: Table S5). According to COG analysis, a preponderance of these novel genes were concentrated in several categories, such as general function prediction only, replication, recombination and repair, transcription, etc.

The diploid $A$. duranensis and A. ipaensis genes (http://www.peanutbase.org) [46] were only annotated using open reading frames (ORFs), and thus most of the $5^{\prime}$ - and 3'-untranslated regions (UTRs) have not been defined. Here by globally comparing the complete transcripts with the reference $A$. duranensis and $A$. ipaensis gene models, we successfully elongated the UTRs of 24,717 genes, there into 9177 were elongated with respect to both the 5 ' - and the 3'-UTR (Additional file 6: Table S6).

AS related to genes associated with fatty acid metabolism Acyl-lipid metabolism is a very important process and plays a myriad of diverse functions in all plants. Arabidopsis acyl-lipid metabolism requires more than 600 genes that involved in at least 120 enzymatic reactions. In total, 2275 peanut genes (Additional file 7: Table S7) associated with fatty acid metabolism were identified in the progenitor genomes (excluding transcription factors and $A B C$ transporters) and can be grouped into 12 lipid classes, including fatty acid synthesis and export, plastid glycerolipid synthesis, eukaryotic phospholipid synthesis, etc. Among the 2275 genes, there are 1724 ones with FPKM $\geq 0.1$. More than half of these (1062, accounted for $61.6 \%$ ) were affected by AS (Additional file 7: Table S7). The high AS ratio indicates the 
Table 5 Comparison of different types of ES events occurred in the four samples of peanut different organs

\begin{tabular}{|c|c|c|c|c|c|c|c|c|}
\hline \multirow[t]{2}{*}{ AS types } & \multicolumn{2}{|l|}{ FH1-seed1 } & \multicolumn{2}{|l|}{ FH1-seed2 } & \multicolumn{2}{|l|}{ FH1-root } & \multicolumn{2}{|l|}{ FH1-leaf } \\
\hline & AS Events & Percentage & AS Events & Percentage & AS Events & Percentage & AS Events & Percentage \\
\hline SKIP_OFF & 3189 & $29.28 \%$ & 3546 & $29.25 \%$ & 3003 & $28.81 \%$ & 2840 & $29.20 \%$ \\
\hline SKIP_ON & 2945 & $27.04 \%$ & 3316 & $27.35 \%$ & 2797 & $26.83 \%$ & 2583 & $26.56 \%$ \\
\hline XSKIP_OFF & 1759 & $16.15 \%$ & 1832 & $15.11 \%$ & 1680 & $16.12 \%$ & 1586 & $16.31 \%$ \\
\hline XSKIP_ON & 1419 & $13.03 \%$ & 1515 & $12.50 \%$ & 1399 & $13.42 \%$ & 1296 & $13.33 \%$ \\
\hline MSKIP_OFF & 593 & $5.44 \%$ & 695 & $5.73 \%$ & 548 & $5.26 \%$ & 527 & $5.42 \%$ \\
\hline MSKIP_ON & 426 & $3.91 \%$ & 554 & $4.57 \%$ & 396 & $3.80 \%$ & 372 & $3.82 \%$ \\
\hline XMSKIP_OFF & 341 & $3.13 \%$ & 396 & $3.27 \%$ & 364 & $3.49 \%$ & 298 & $3.06 \%$ \\
\hline XMSKIP_ON & 219 & $2.01 \%$ & 270 & $2.23 \%$ & 236 & $2.26 \%$ & 224 & $2.30 \%$ \\
\hline Total & 10,891 & $100.00 \%$ & 12,124 & $100.00 \%$ & 10,423 & $100.00 \%$ & 9726 & $100.00 \%$ \\
\hline
\end{tabular}

SKIP Skipped exon (SKIP_ON, SKIP_OFF pair), XSKIP Approximate SKIP (XSKIP_ON, XSKIP_OFF pair), MSKIP Multi-exon SKIP (MSKIP_ON, MSKIP_OFF pair), XMSKIP Approximate MSKIP (XMSKIP_ON, XMSKIP_OFF pair)

importance of AS in the regulation of fatty acid metabolism. Genes associated with fatty acid synthesis formed the largest group (422 members, of which 226 experienced AS). The 3-ketoacyl-CoA synthase gene family comprised 49 members, but only nine $(<20 \%)$ were affected by AS. In contrast, in the acyl-CoA thioesterase gene family, the frequency was $75 \%$.

Polymerase Chain Reactions (PCR) and sequencings were applied to three genes encoding fatty acid desaturase (FAD) (Aradu.5N10F, Araip.84LR8 and Araip.92Q2X) to validate the presence of AS as predicted from the sequence data (Additional file 4: Table S4). Sequencing of the PCR amplicons established the presence of novel exons among these AS transcripts (Fig. 5). Compared with Aradu.5N10F, Aradu.5N10F01 had gained a new fifth exon; compared with Araip.84LR8, Araip.84LR801 had gained a new second exon; and compared with Araip.92Q2X, Araip.92Q2X01 and Araip.92Q2X02 both gained a new second exon. The difference between Araip.92Q2X01 and Araip.92Q2X02 was due to a 3'-AE event affecting the seventh exon, but these AS events did not influence the translation; all the isoforms could translate into complete protein. By blast these encoded protein sequences in NCBI Nr database we found that they all belonged to FAD gene family.

\section{Discussion}

Since the original discovery that genes can generate multiple transcripts [47], it has become clear that the AS phenomenon is ubiquitous in eukaryote genomes $[8,12,13,28-30,36,38,49-51]$. The development of high throughput sequencing technologies has allowed for genome-wide scans of AS to be undertaken, resulting in estimates that at least $42 \%$ of the intron-containing genes of $A$. thaliana experience AS [31]. According to Zhang et al. [49], the mean number of transcripts generated per gene is 2.4. The proportion of genes which experience AS in plants varied greatly [26]. The proportion of peanut genes thus affected, as estimated here, was about $37.2 \%$, lower than that in tomato, Arabidopsis and soybean [25, 37, 50]. There are several reasons for this: first, the number of the samples we used was less, (seed1, seed2, root and leaf), many genes or AS genes expressed specifically in stem,

Table 6 Comparison of different types of IR events occurred in the four samples of peanut different organs

\begin{tabular}{|c|c|c|c|c|c|c|c|c|}
\hline \multirow[t]{2}{*}{ AS types } & \multicolumn{2}{|l|}{ FH1-seed1 } & \multicolumn{2}{|l|}{ FH1-seed2 } & \multicolumn{2}{|l|}{ FH1-root } & \multicolumn{2}{|l|}{ FH1-leaf } \\
\hline & AS Events & Percentage & AS Events & Percentage & AS Events & Percentage & AS Events & Percentage \\
\hline IR_OFF & 9331 & $30.17 \%$ & 7584 & $30.60 \%$ & 6573 & $30.70 \%$ & 7986 & $30.88 \%$ \\
\hline IR_ON & 10,261 & $33.17 \%$ & 8451 & $34.09 \%$ & 7331 & $34.24 \%$ & 8802 & $34.03 \%$ \\
\hline XIR_OFF & 2806 & $9.07 \%$ & 2195 & $8.86 \%$ & 2028 & $9.47 \%$ & 2350 & $9.09 \%$ \\
\hline XIR_ON & 3400 & $10.99 \%$ & 2803 & $11.31 \%$ & 2516 & $11.75 \%$ & 2905 & $11.23 \%$ \\
\hline MIR_OFF & 1700 & $5.50 \%$ & 1179 & $4.76 \%$ & 892 & $4.17 \%$ & 1350 & $5.22 \%$ \\
\hline MIR_ON & 2133 & $6.90 \%$ & 1529 & $6.17 \%$ & 1191 & $5.56 \%$ & 1720 & $6.65 \%$ \\
\hline XMIR_OFF & 526 & $1.70 \%$ & 402 & $1.62 \%$ & 344 & $1.61 \%$ & 296 & $1.14 \%$ \\
\hline XMIR_ON & 774 & $2.50 \%$ & 645 & $2.60 \%$ & 533 & $2.49 \%$ & 456 & $1.76 \%$ \\
\hline Total & 30,931 & $100.00 \%$ & 24,788 & $100.00 \%$ & 21,408 & $100.00 \%$ & 25,865 & $100.00 \%$ \\
\hline
\end{tabular}

IR Intron retention (IR_ON, IR_OFF pair), XIR Approximate IR (XIR_ON, XIR_OFF pair), MIR Multi-IR (MIR_ON, MIR_OFF pair), XMIR Approximate MIR (XMIR_ON, XMIR_OFF pair) 

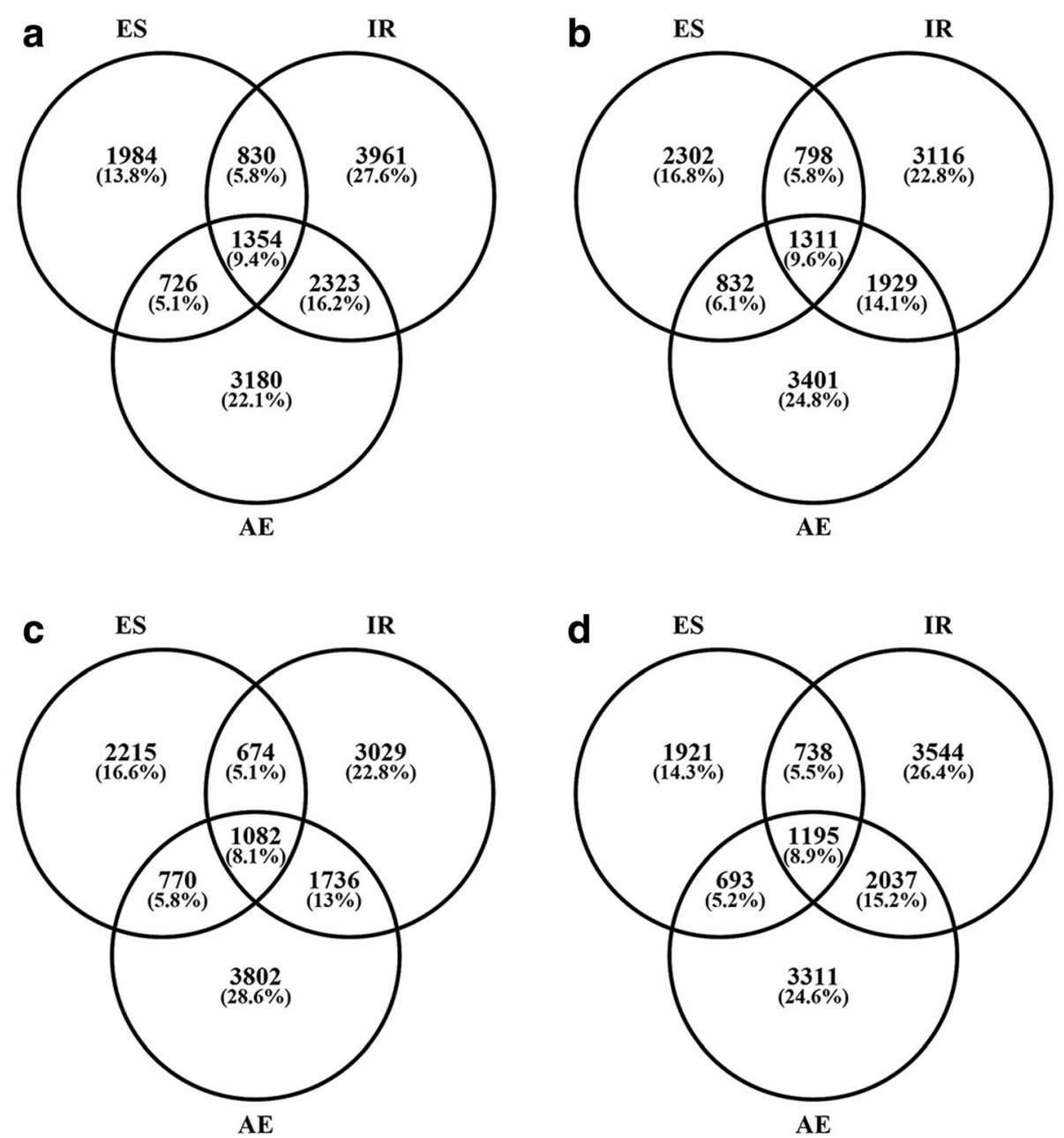

Fig. 2 Venn diagram depicting the gene number of the three types of AS events occurred in the four peanut organs. $\mathbf{a}$, FH1-seed1; b, FH1-seed2; c, FH1-root; d, FH1-leaf

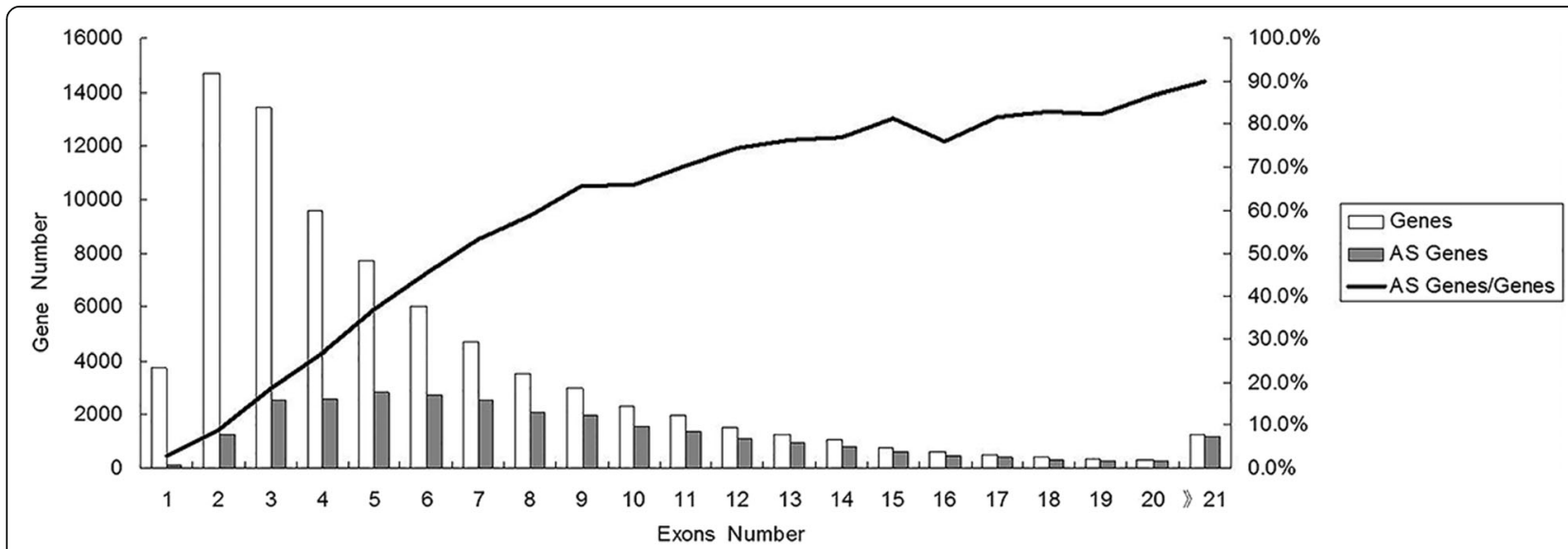

Fig. 3 Comparison of the exon number between the total genes and AS genes in peanut genome. The number in $X$ axes indicated the number of exons contained in the genes, the left $Y$ axes indicated the number of the genes containing these exons, and the right $Y$ axes indicated the ratio of AS genes/total genes with the same number of exons 


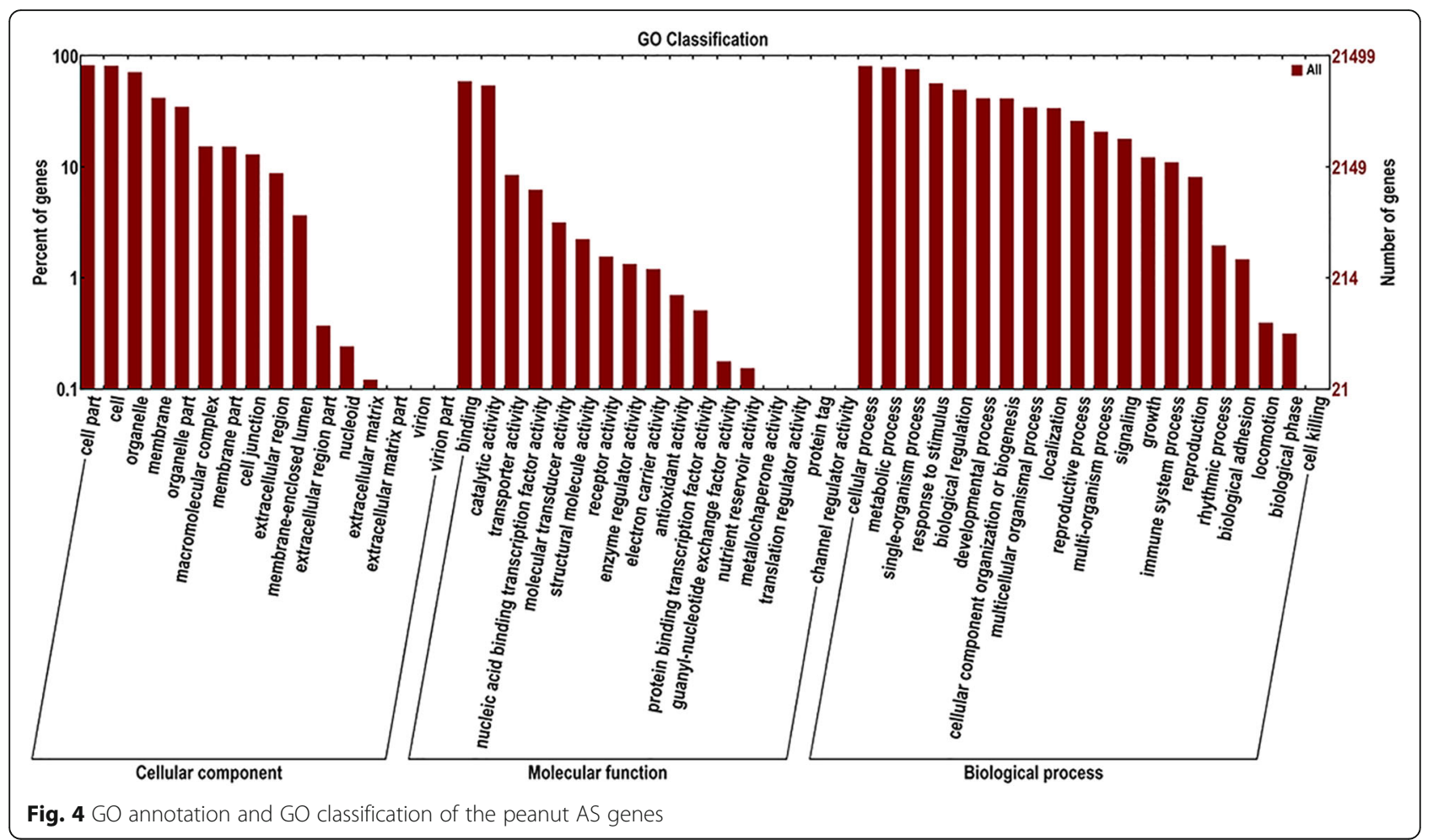

flower and other tissues were not detected. Many reports showed that AS ratio was related to the sample number, the more samples, the greater the AS ratio $[25,32,50]$. Second, our samples were collected from different developmental stages and did not include samples from different circumstances, so that many genes or AS genes expressed specifically in stress conditions were not detected. It is reported that numerous AS events are induced only by abiotic and biotic stresses [25, 39]. Additionally, the AS ratio discovered within the same tissues and growth conditions is different because of prediction algorithms used [52-54]. In comparison with Arabidopsis and other plants, the study of AS events in peanut was considerably lagged. Here we identified 27,829 peanut genes underwent AS events, about half of the AS genes were constitutively alternatively spliced in all of the four samples, the others showed dramatically differential tissue expression pattern.
Though many AS events regulated by tissue specific cues, it seems that AS plays a particular important role in seed development, for more AS events and AS isoforms were detected in seed than in root and leaf in this study (Tables 1 and 2, Additional file 4: Table S4). Seed is a very important organ of generation containing a mixture of many different tissues. Similar results were also reported in previous researches [25, 50]. Thatcher et al. found that maize seed had more AS isoforms than endosperm and embryo, and there were larger amount of AS isoforms found only in seed [30]. In tomato, the fruits generated more AS isoforms per gene than that of flowers and other organs [50]. Shen et al. found that more AS events occurred in the younger developmental stages than in the older developmental stages for the same type of tissue [25].

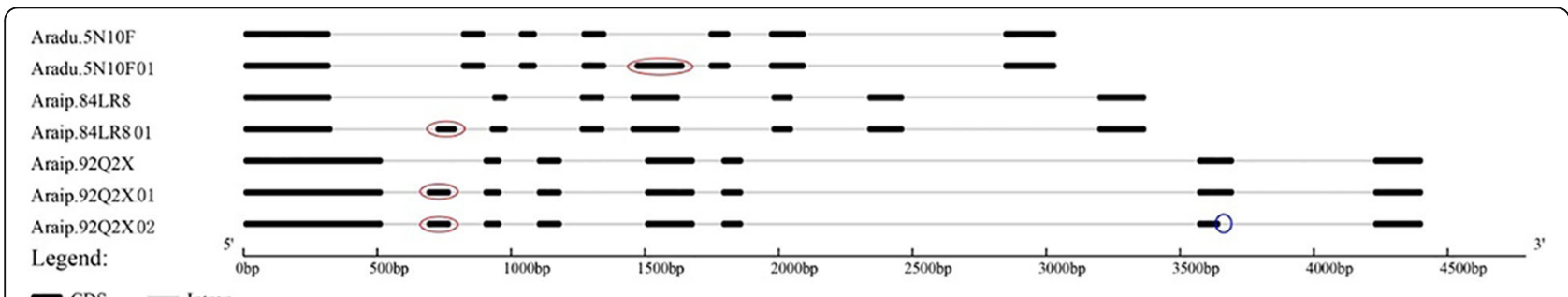

- $\operatorname{cDS}$ - Intron

Fig. 5 Experimental identification of the AS isoforms of three peanut FAD genes. Red oval indicating the new exons; Blue circle indicating the $3^{\prime}-A E$ 
It is interesting that more than half of peanut AS genes experienced only a single type of event (Fig. 2a), it means that more peanut AS genes prefer only one AS type to regulate its expression pattern. Potenza et al. reported this phenomenon in grapevine, about $49.7 \%$ grapevine AS genes experienced mainly once or twice AS events [51]. It is reported that gene structure has significant influence on AS event types and AS frequency, such as intron length, exon number, gene expression level, etc. [25]. With the increase in the intron length, the proportion of ES increased whereas the proportion of IR decreased; with the increase in the gene expression, the proportion of IR increased, and the proportion of ES decreased [25].

TSS and TTS are commonly detected in different peanut organs. Protein synthesis at the ribosome was directed by the messenger RNA (mRNA) template, so the secondary mRNA structures might influence the translation initiation. Now accumulating researches show that mRNAs could produce protein isoforms owing to the use of TSS, especially in human and mouse [55-59]. In mammals, the TSS transcripts are regulated in a tissue-specific manner and/or developmental stage-specific manner [60]. N-terminomics data shows that in higher eukaryotes around $20 \%$ of all identified protein $\mathrm{N}$ termini point to such TSS [59]. In plants, studies focusing on TSS have been achieved some progresses. Kitagawa et al. identified many putative TSSs in rice and verified them using Reverse Transcription-Polymerase Chain Reaction (RT-PCR), results showed that TSSs of rice are less diverse than mouse and some of which are regulated in a tissue-specific manner [61]. Another example is the Arabidopsis SYN1 gene, it utilizes alternative promoters and splicing to produce two isoforms with different 5 '-ends [62]. Thousands of human and mouse genes generate mRNA isoforms differing in their 3' UTRs which containing many regulatory elements involved in many cellular processes $[63,64]$. Till now, the reason why TTS is so abundant and conserved is still a question. Some research reported that TTS is related to RNA localization, transcript stability and protein production [65], but a recently genome-wide analysis showed acontrary result [66]. TTS could also increase transcription protein diversity. Fontana et al. find a new regulatory mechanism of Brahma (BRM), oxidative stress controls the choice of TTS via a Brahma-BRCA1-CstF pathway [67]. Potenza et al. investigated the location of the AS events in multiple cultivars and found that $86 \%$ AS events fall in coding exons, the others occurred in UTR or UTR-CDS [51]. Vitulo et al. found that, in grape, 18 and $11 \%$ of all AS events occur at the 5'UTR and 3'UTR regions, and about $1 \%$ of the AS events occurred in UTR-CDS [27]. In this study, many TSS and TTS splicing events were identified, and they expressed in a tissue-specific manner (Fig. 5). We think the ratio may be overestimated.
The main reason is that most genes in wild type peanut genome were predicted and their UTRs were not identified by experiments, so their UTRs are agnostic. A second reason is that cultivated peanut is allotetraploid, and their genotypic milieu will be more complex than their ancestry. It is reported that whole-genome duplication plays a crucial ploidy-dependent role in AS [28]. These researches indicate that all regions of the transcript are susceptible to AS without any significant preference.

Fatty acid metabolism is a key process in oilseed plants, but little effort has been made to date to define the contribution of AS to this aspect. Thambugala et al. identified six desaturase genes in flax and found some of the SAD and FAD isoforms have significant effects on fatty acid composition, oil content and iodine value [68]. Later, Radovanovic et al. found that all FAD2 isoforms were active, two FAD3A and three FAD3B isoforms were not functional and some of them were caused by the presence of premature stop codon [69]. Here we found that the peanut genome harbors some 1062 genes (FPKM $\geq 0.1$ ) related to fatty acid synthesis/metabolism, of which around $61.6 \%$ were predicted to experience AS; this high proportion suggests that AS likely has a major influence over fatty acid metabolism. Experimental validation of three FADs showed that there indeed exist many AS isoforms in fatty acid metabolism related genes in peanut. But the function of the isoforms needs further study.

\section{Conclusions}

We identified 27,829 AS genes in peanut transcriptome with strand-specific RNA-Seq technique. The occurrence rate of AS genes increased along with the exon number increasing. AS was more frequent in the seed, some of AS genes were organ-specific, the predominant form of AS was intron retention. We analyzed in detail the GO annotation and GO classification of the peanut AS genes. We have cloned some genes to validate the presence of some AS genes as predicted from the sequence data. This identification will have strong impact in the area of peanut study.

\section{Methods}

RNA isolation, quantification and qualification

Four RNA libraries were developed from a peanut cultivar 'Fenghua1': "FH1-seed1" was prepared from seed harvested 30 days after flowering (DAF), "FH1-seed2" from seed harvested after 50 DAF, and both "FH1-root" and "FH1-leaf" from 12 day old seedlings. Each library was based on tissue collected from at least three plants, which was snap-frozen in liquid nitrogen prior to RNA isolation. RNA was extracted using the TRIzol reagent (Invitrogen, Carlsbad, CA, USA) then treated with RNase-free DNase I (New England Biolabs, USA) for $30 \mathrm{~min}$ at $37{ }^{\circ} \mathrm{C}$ to degrade any contaminating DNA 
present. The concentration and purity of the resulting RNA preparations were assessed using a NanoDrop 2000 spectrophotometer (Thermo Fisher Scientific, Wilmington, DE, USA) and its integrity was checked using an RNA Nano 6000 Assay Kit (Agilent Technologies, CA, USA).

\section{CDNA library construction and sequencing}

A $1.5 \mu \mathrm{g}$ aliquot of RNA was processed with a Ribo-Zero rRNA Removal Kit (Epicentre, Madison, WI, USA) to remove the rRNA component, and the subsequently prepared sequencing libraries based on the residual RNA, following treatment with an NEBNext ${ }^{\circ}$ UltraTM Directional RNA Library Prep Kit for Illumina ${ }^{\circ}$ (New England Biolabs, USA). Index codes were added to enable each sequence to be attributed its organ provenance. Paired-end sequences were generated by an Illumina Hiseq2500 platform.

\section{Quantification of gene and transcript abundances and prediction of AS events}

After removal of low quality reads and adapter sequences, the sequences were mapped onto the reference peanut genome (https://www.peanutbase.org/) [46] with the aid of TopHat2 software (http://ccb.jhu.edu/software/tophat/ index.shtml). The cuffdiff routine within Cufflinks software (http://cufflinks.cbcb.umd.edu/) was used to quantify gene and transcript abundances, based on the FPKM [70]. Transcripts associated with an FPKM greater than 0.1 within a given library were selected as the expression indicator. The overall gene FPKMs were computed by summing the FPKMs of component transcripts. The assembled transcripts were mapped to their corresponding gene model using the Cuffcompare module within the Cufflinks package. AS events was identified using ASprofile software (http://ccb.jhu.edu/software/ASprofile/).

\section{Functional annotation}

Gene function annotation was carried out using a combination of software, tools and databases. InterProScan was used for searching the protein domains and functional sites integrating several different databases (PROSITE, PRINTS, Pfam, ProDom and SMART) [71].The $\mathrm{Nr}$ [72], KOG/COG [73], Swiss-Prot [74], KEGG [75] and GO [76] databases were blast at the protein level on the peanut genes.

\section{Experimental validation of alternative transcripts produced by genes encoding FAD}

A $5 \mu \mathrm{g}$ aliquot of RNA from the FH1-seed1 library was reverse transcribed in a $20 \mu \mathrm{L}$ reaction using a cDNA synthesis kit (Invitrogen, Carlsbad, CA, USA). Two primers pairs were designed, one targeting Araip.92Q2X and the other Aradu.5N10F and Araip.84LR8. The sequences of the former pair (92Q2X-F/-R) were 5'-TGTGCGTGTTTCATTCACCCTCT/5'-AGGA ATTGTGTCATGTGCCTCAT, while those of the latter pair (5N10F-F/-R) were 5'-CATTTTCTCCCACACA CTAACTTG and 5'-TGATCATTTAGACTTGTCCGA AG. Each $50 \mu \mathrm{L}$ RT-PCR contained $100 \mathrm{ng} / \mu \mathrm{L}$ cDNA, $1.5 \mu \mathrm{L}$ of each primer $(10 \mu \mathrm{M}), 5 \mu \mathrm{L} 10 \times$ PCR buffer (Transgen Biotech, Peking, China), $2.5 \mu \mathrm{L} 2.5 \mathrm{mM}$ dNTP and $1 \mathrm{U}$ Trans TaqHiFi DNA polymerase (Transgen Biotech, Peking, China). The reactions were denatured $\left(94{ }^{\circ} \mathrm{C} / 4 \mathrm{~min}\right)$, cycled 30 times through $94{ }^{\circ} \mathrm{C} / 30 \mathrm{~s}$, $58{ }^{\circ} \mathrm{C} / 30 \mathrm{~s}, 72{ }^{\circ} \mathrm{C}(120 \mathrm{~s})$, and finally held at $72{ }^{\circ} \mathrm{C}$ for $10 \mathrm{~min}$. The PCR products were purified using a MinElute $^{\mathrm{Tt}}$ Gel Extraction Kit (Qiagen, Hilden, Germany) and inserted into the pEASY-T3 vector (Transgen Biotech, Peking, China) for sequencing. Sequences were compared using DNAMAN software (http://www.lynnon.com/index.html), and gene structures were drawn using Gene Structure Display Server online (http://gsds.cbi.pku.edu.cn/).

\section{Additional files}

Additional file 1: Table S1. Sequencing results from the four peanut samples. (DOCX $16 \mathrm{~kb}$ )

Additional file 2: Table S2. Genome alignment results of the clean data from the four samples. (DOC $31 \mathrm{~kb}$ )

Additional file 3: Table S3. The number of the isoforms of the AS genes. (XLSX $1826 \mathrm{~kb}$ )

Additional file 4: Table S4. Expression level of all isoforms. (XLSX 16864 kb)

Additional file 5: Table S5. Annotation of the new genes. (XLSX 1294 kb)

Additional file 6: Table S6. Optimization of the gene structures. (XLSX $2040 \mathrm{~kb}$ )

Additional file 7: Table S7. Fatty acid related genes. (XLSX 250 kb)

\section{Abbreviations}

AE: Alternative exon ends; AS: Alternative splicing; BRM: Brahma; DAF: Days after flowering; ES: Exon skipping; FAD: Fatty acid desaturase; FPKM: Fragments per kilobase of exon per million fragments mapped; GO: Gene Ontology; IR: Intron retention; KEGG: Sequences Kyoto Encyclopedia of Genes and Genomes; KOG/COG: Clusters of Orthologous Groups of proteins; MiRNAs: MicroRNAs; mRNA: Messenger RNA; MSKIP: Multiple exon skipping; Nr: Non-redundant protein sequences; ORFs: Open reading frames; PCR: Polymerase Chain Reaction; RT-

PCR: Reverse Transcription-Polymerase Chain Reaction; TSS: Transcription start site; TTS: Transcription terminal site; UTRs: 5'- and 3'-untranslated regions

\section{Acknowledgements}

Not applicable.

\section{Funding}

This work was supported by the National Natural Science Foundation of China (31470349), Shandong Province Germplasm Innovation (2014-2017), International Science \& Technology Cooperation Program of China (2015DFA31190), the Supporting Plan of National Science and Technology of China (2014BAD11B04) and the earmarked fund for Modern Agroindustry Technology Research System (CARS-14). The founders had no role in study design, data collection and analysis, decision to publish, or preparation of the manuscript. 


\section{Availability of data and materials}

The sequencing data for the CDNA library and other analyzed datasets are available under NCBI BioProject database under accession number PRJNA354652. All the supporting data are included as additional files.

\section{Authors' contributions}

JR and FG acquired data, YW and XL analyzed and interpreted data, LS performed PCR amplification and sequecing, LS, SW and ZP participated in design and drafting of the manuscript, revised the manuscript and gave final approval of the version to be published. All authors read and approved the final manuscript.

\section{Ethics approval and consent to participate}

Not applicable.

\section{Competing interests}

The authors declare that they have no competing interests.

\section{Publisher's Note}

Springer Nature remains neutral with regard to jurisdictional claims in published maps and institutional affiliations.

\section{Author details}

${ }^{1}$ College of Life Science, Shandong University, Jinan, China. ${ }^{2}$ Bio-Tech Research Center, Shandong Academy of Agricultural Science/Shandong Provincial Key Laboratory of Genetic Improvement, Ecology and Physiology of Crops, Jinan, China.

\section{Received: 9 August 2017 Accepted: 4 June 2018}

Published online: 04 July 2018

\section{References}

1. Reddy AS, Marquez Y, Kalyna M, Barta A. Complexity of the alternative splicing landscape in plants. Plant Cell. 2013;25(10):3657-83.

2. Stamm S, Ben-Ari S, Rafalska I, Tang Y, Zhang Z, Toiber D, Thanaraj TA Soreq H. Function of alternative splicing. Gene. 2005;344:1-20.

3. Scotti MM, Swanson MS. RNA mis-splicing in disease. Nat Rev Genet. 2016; 17(1):19-32.

4. Le KQ, Prabhakar BS, Hong WJ, Li LC. Alternative splicing as a biomarker and potential target for drug discovery. Acta Pharmacol Sin. 2015;36(10):1212-8.

5. Kornblihtt AR, Schor IE, Allo M, Dujardin G, Petrillo E, Munoz MJ. Alternative splicing: a pivotal step between eukaryotic transcription and translation. Nat Rev Mol Cell Biol. 2013;14(3):153-65.

6. Chabot B, Shkreta L. Defective control of pre-messenger RNA splicing in human disease. J Cell Biol. 2016;212(1):13-27.

7. Caceres JF, Kornblihtt AR. Alternative splicing: multiple control mechanisms and involvement in human disease. Trends Genet. 2002;18(4):186-93.

8. Rodriguez SA, Grochova D, McKenna T, Borate B, Trivedi NS, Erdos MR, Eriksson M. Global genome splicing analysis reveals an increased number of alternatively spliced genes with aging. Aging Cell. 2016;15(2):267-78.

9. Yang S, Tang F, Zhu H. Alternative splicing in plant immunity. Int J Mol Sci. 2014;15(6):10424-45.

10. Remy E, TR C, Batista RA, Hussein MA, Teixeira MC, Athanasiadis A, SaCorreia I, Duque P. Intron retention in the $5^{\prime}$ UTR of the novel ZIF2 transporter enhances translation to promote zinc tolerance in arabidopsis. PLoS Genet. 2014;10(5):e1004375.

11. Blencowe BJ. Alternative splicing: new insights from global analyses. Cell. 2006;126(1):37-47.

12. Zhang Q, Zhang X, Wang S, Tan C, Zhou G, Li C. Involvement of alternative splicing in barley seed germination. PLoS One. 2016;11(3):e0152824.

13. Tang W, Zheng Y, Dong J, Yu J, Yue J, Liu F, Guo X, Huang S, Wisniewski M, Sun J, et al. Comprehensive transcriptome profiling reveals long noncoding RNA expression and alternative splicing regulation during fruit development and ripening in kiwifruit (Actinidia chinensis). Front Plant Sci. 2016:7:335

14. Xing $Y$, Lee C. Alternative splicing and RNA selection pressure-evolutionary consequences for eukaryotic genomes. Nat Rev Genet. 2006:7:499-509.

15. Keren $\mathrm{H}$, Levmaor G, Ast G. Alternative splicing and evolution: diversification, exon definition and function. Nat Rev Genet. 2010;11(5): 1031-34.

16. Boue S, Letunic I, Bork P. Alternative splicing and evolution. Bioessays. 2003; 25(11):1031-4
17. Florea L, Song L, Salzberg SL. Thousands of exon skipping events differentiate among splicing patterns in sixteen human tissues. F1000Research. 2013;2:188

18. Barbosa-Morais NL, Irimia M, Pan Q, Xiong HY, Gueroussov S, Lee L, Slobodeniuc V, Kutter C, Watt S, Colak R, et al. The evolutionary landscape of alternative splicing in vertebrate species. Science. 2012 338(6114):1587-93.

19. Merkin J, Russell C, Chen P, Burge CB. Evolutionary dynamics of gene and isoform regulation in mammalian tissues. Science. 2012;338(6114):1593-9.

20. Sultan M, Schulz MH, Richard H, Magen A, Klingenhoff A, Scherf M, Seifert M, Borodina T, Soldatov A, Parkhomchuk D, et al. A global view of gene activity and alternative splicing by deep sequencing of the human transcriptome. Science. 2008:321(5891):956-60.

21. Pan Q, Shai O, Lee LJ, Frey BJ, Blencowe BJ. Deep surveying of alternative splicing complexity in the human transcriptome by high-throughput sequencing. Nat Genet. 2008;40(12):1413-5.

22. Wang ET, Sandberg R, Luo S, Khrebtukova I, Zhang L, Mayr C, Kingsmore SF, Schroth GP, Burge CB. Alternative isoform regulation in human tissue transcriptomes. Nature. 2008:456(7221):470-6.

23. Graveley B, Brooks AN, Carlson JW, Duff MO, Landolin JM, Yang L, Artieri CG, Baren MJ, Boley N, Booth BW, et al. The developmental transcriptome of Drosophila melanogaster. Nature. 2011;471(7339):473-9.

24. Xu Q, Modrek B, Lee C. Genome-wide detection of tissue-specific alternative splicing in the human transcriptome. Nucleic Acids Res. 2002;30(17):3754-66.

25. Shen Y, Zhou Z, Wang Z, Li W, Fang C, Wu M, Ma Y, Liu T, Kong LA, Peng $\mathrm{DL}$, et al. Global dissection of alternative splicing in paleopolyploid soybean Plant Cell. 2014;26(3):996-1008.

26. Huang J, Gao Y, Jia H, Liu L, Zhang D, Zhang Z. Comparative transcriptomics uncovers alternative splicing changes and signatures of selection from maize improvement. BMC Genomics. 2015;16:363.

27. Vitulo N, Forcato C, Carpinelli EC, Telatin A, Campagna D, D'Angelo M, Zimbello R, Corso M, Vannozzi A, Bonghi C, et al. A deep survey of alternative splicing in grape reveals changes in the splicing machinery related to tissue, stress condition and genotype. BMC Plant Biol. 2014:14:99.

28. Saminathan T, Nimmakayala P, Manohar S, Malkaram S, Almeida A, Cantrell R, Tomason Y, Abburi L, Rahman MA, Vajija VG, et al. Differential gene expression and alternative splicing between diploid and tetraploid watermelon. J Exp Bot. 2015;66(5):1369-85.

29. Du Q, Li C, Li D, Lu S. Genome-wide analysis, molecular cloning and expression profiling reveal tissue-specifically expressed, feedback-regulated, stress-responsive and alternatively spliced novel genes involved in gibberellin metabolism in Salvia miltiorrhiza. BMC Genomics. 2015;16:1087.

30. Thatcher SR, Danilevskaya ON, Meng X, Beatty M, Zastrow-Hayes G, Harris C, Van Allen B, Habben J, Li B. Genome-wide analysis of alternative splicing during development and drought stress in maize. Plant Physiol. 2016;170(1): 586-99.

31. Filichkin SA, Priest HD, Givan SA, Shen R, Bryant DW, Fox SE, Wong WK, Mockler TC. Genome-wide mapping of alternative splicing in Arabidopsis thaliana. Genome Res. 2010;20(1):45-58.

32. Thatcher SR, Zhou W, Leonard A, Wang B-B, Beatty M, Zastrow-Hayes G, Zhao X, Baumgarten A, Li B. Genome-wide analysis of alternative splicing in Zea mays: landscape and genetic regulation. Plant Cell. 2014;26:3472-87.

33. Li $\mathrm{Q}$, Xiao G, Zhu YX. Single-nucleotide resolution mapping of the Gossypium raimondii transcriptome reveals a new mechanism for alternative splicing of introns. Mol Plant. 2014;7(5):829-40.

34. Calarco JA, Xing Y, Caceres M, Calarco JP, Xiao X, Pan Q, Lee C, Preuss TM, Blencowe BJ. Global analysis of alternative splicing differences between humans and chimpanzees. Genes Dev. 2007;21(22):2963-75.

35. Kianianmomeni A, Ong CS, Ratsch G, Hallmann A. Genome-wide analysis of alternative splicing in Volvox carteri. BMC Genomics. 2014:15:1117.

36. Mandadi KK, Scholthof KB. Genome-wide analysis of alternative splicing landscapes modulated during plant-virus interactions in Brachypodium distachyon. Plant Cell. 2015;27(1):71-85

37. Marquez Y, Brown JW, Simpson C, Barta A, Kalyna M. Transcriptome survey reveals increased complexity of the alternative splicing landscape in Arabidopsis. Genome Res. 2012;22(6):1184-95.

38. Min XJ, Powell B, Braessler J, Meinken J, Yu F, Sablok G. Genome-wide cataloging and analysis of alternatively spliced genes in cereal crops. BMC Genomics. 2015;16:721

39. Staiger D, Brown JW. Alternative splicing at the intersection of biological timing, development, and stress responses. Plant Cell. 2013;25(10):3640-56. 
40. Remy E, Cabrito TR, Baster P, Batista RA, Teixeira MC, Friml J, Sa-Correia I, Duque P. A major facilitator superfamily transporter plays a dual role in polar auxin transport and drought stress tolerance in Arabidopsis. Plant Cell. 2013;25(3):901-26.

41. Lewis BP, Green RE, Brenner SE. Evidence for the widespread coupling of alternative splicing and nonsense-mediated mRNA decay in humans. Proc Natl Acad Sci U S A. 2003;100(1):189-92.

42. Ottens F, Gehring NH. Physiological and pathophysiological role of nonsense-mediated mRNA decay. Pflugers Arch - Eur J Physiol. 2016;468(6): 1013-28.

43. Wang BB, Brendel V. Genomewide comparative analysis of alternative splicing in plants. Proc Natl Acad Sci U S A. 2006;103(18):7175-80.

44. Drechsel G, Kahles A, Kesarwani AK, Stauffer E, Behr J, Drewe P, Ratsch G, Wachter A. Nonsense-mediated decay of alternative precursor mRNA splicing variants is a major determinant of the Arabidopsis steady state transcriptome. Plant Cell. 2013;25(10):3726-42.

45. Kalyna M, Simpson CG, Syed NH, Lewandowska D, Marquez Y, Kusenda B, Marshall J, Fuller J, Cardle L, McNicol J, et al. Alternative splicing and nonsense-mediated decay modulate expression of important regulatory genes in Arabidopsis. Nucleic Acids Res. 2012;40(6):2454-69.

46. Bertioli DJ, Cannon SB, Froenicke L, Huang G, Farmer AD, Cannon EK, Liu X, Gao D, Clevenger J, Dash S, et al. The genome sequences of Arachis duranensis and Arachis ipaensis, the diploid ancestors of cultivated peanut. Nat Genet. 2016;48(4):438-46.

47. Kopelman NM, Lancet D, Yanai I. Alternative splicing and gene duplication are inversely correlated evolutionary mechanisms. Nat Genet. 2005;37(6): 588-9.

48. Modrek B, Lee C: A genomic view of alternative splicing. Nature genetics 2002, 30(1):13-9.

49. Zhang R, Calixto CPG, Marquez Y, Venhuizen P, Tzioutziou NA, Guo W, Spensley M, Entizne JC, Lewandowska D, St H, et al. A high quality Arabidopsis transcriptome for accurate transcript-level analysis of alternative splicing. Nucleic Acids Res. 2017;45(9):5061-73.

50. Sun $Y$, Xiao H. Identification of alternative splicing events by RNA sequencing in early growth tomato fruits. Genomics. 2015;16(1):948.

51. Potenza E, Racchi ML, Sterck L, Coller E, Asquini E, Tosatto SCE, Velasco R, Peer $\mathrm{V}$, Cestaro A. Exploration of alternative splicing events in ten different grapevine cultivars. BMC Genomics. 2015;16(1):1-9

52. Trapnell C, Pachter L, Salzberg SL. TopHat: discovering splice junctions with RNA-Seq. Bioinformatics. 2009;25:1105-11.

53. Foissac S, Sammeth M. ASTALAVISTA: dynamic and flexible analysis of alternative splicing events in custom gene datasets. Nucleic Acids Res. 2007; 35(Web Server issue):W297-9.

54. Trapnell C, Roberts A, Goff L, Pertea G, Kim D, Kelley DR, Pimentel H, Salzberg SL, Rinn JL, Pachter L. Differential gene and transcript expression analysis of RNA-seq experiments with TopHat and cufflinks. Nat Protoc. 2012;7(3):562-78.

55. Gandre S, Bercovich Z, Kahana C. Mitochondrial localization of antizyme is determined by context-dependent alternative utilization of two AUG initiation codons. Mitochondrion. 2003;2:245-56.

56. Leissring MA, Farris W, Wu X, Christodoulou DC, Haigis MC, Guarente L, Selkoe DJ. Alternative translation initiation generates a novel isoform of insulin-degrading enzyme targeted to mitochondria. Biochem J. 2004;383: 439-46.

57. Kaipio K, Kallio J, Pesonen U. Mitochondrial targeting signal in human neuropeptide Y gene. Biochem Biophys Res Commun. 2005;337:633-40.

58. Kochetov AV. Alternative translation start sites and hidden coding potential of eukaryotic mRNAs. Bioessays. 2008;30:683-91.

59. Damme PV, Gawron D, Criekinge WV, Menschaert G. N-terminal proteomics and ribosome profiling provide a comprehensive view of the alternative translation initiation landscape in mice and men. Mol Cell Proteomics. 2014; 13:1245-61.

60. Jackson RJ. Alternative mechanisms of initiating translation of mammalian mRNAs. Biochem Soc Trans. 2005;33:1231-41.

61. Kitagawa N, Washio T, Kosugi S, Yamashita T, Higashi K, Yanagawa H, Higo K, Satoh K, Ohtomo Y, Sunako T, et al. Computational analysis suggests that alternative first exons are involved in tissue-specific transcription in rice (Oryza sativa). Bioinformatics. 2005;21(9):1758-63.

62. Bai X, Peirson BN, Dong F, Xue C, Makaroff CA. Isolation and characterization of SYN1, a RAD21-like gene essential for meiosis in Arabidopsis. Plant Cell. 1999;11:417-30.
63. Taliaferro JM, Vidaki M, Oliveira R, Olson S, Zhan L, Saxena T, Wang ET, Graveley BR, Gertler FB, Swanson MS, et al. Distal alternative last exons localize mRNAs to neural projections. Mol Cell. 2016;61(6):821-33.

64. Miura P, Shenker S, Andreu-Agullo C, Westholm JO, Lai EC. Widespread and extensive lengthening of 3 ' UTRs in the mammalian brain. Genome Res. 2013;23(5):812-25

65. Andreassi C, Riccio A. To localize or not to localize: mRNA fate is in 3'UTR ends. Trends Cell Biol. 2009;19:465-74.

66. Spies N, Burge CB, Bartel DP. 3'UTR-isoform choice has limited influence on the stability and translational efficiency of most mRNAs in mouse fibroblasts. Genome Res. 2013:23:2078-90.

67. Fontana GA, Rigamonti A, Lenzken SC, Filosa G, Alvarez R, Calogero R, Bianchi ME, Barabino SML. Oxidative stress controls the choice of alternative last exons via a Brahma-BRCA1-CstF pathway. Nucleic Acids Res Italic. 2017; 45(2):902-14.

68. Thambugala D, Duguid S, Loewen E, Rowland G, Booker H, You FM, Cloutier S. Genetic variation of six desaturase genes in flax and their impact on fatty acid composition. Theor Appl Genet. 2013;126(10):2627-41.

69. Radovanovic N, Thambugala D, Duguid S, Loewen E, Cloutier S. Functional characterization of flax fatty acid desaturase FAD2 and FAD3 isoforms expressed in yeast reveals a broad diversity in activity. Mol Biotechnol. 2014; 56(7):609-20.

70. Trapnell C, Williams BA, Pertea G, Mortazavi A, Kwan G, Baren MJ, Salzberg SL, Wold BJ, Pachter L. Transcript assembly and quantification by RNA-Seq reveals unannotated transcripts and isoform switching during cell differentiation. Nat Biotechnol. 2010;28:511-5.

71. Zdobnov EM, Apweiler R. InterProScan-an integration platform for the signature-recognition methods in InterPro. Bioinforma Oxf Engl. 2001;17(9): 847-8.

72. Deng YY, Li JQ, Wu SF, Zhu YP, Chen YW, He FC. Integrated NR database in protein annotation system and its localization. Comp Eng Italic. 2006;32(5): $71-4$

73. Tatusov RL, Galperin MY, Natale DA. The COG database: a tool for genome scale analysis of protein functions and evolution. Nucleic Acids Res Italic. 2000;28(1):33-6.

74. Apweiler R, Bairoch A, Wu CH, Barker WC, Boeckmann B, Ferro S, Gasteiger E, Huang H, Lopez R, Magrane M, et al. UniProt: the universal protein knowledgebase. Nucleic Acids Res Italic. 2004;32(Database issue):D115-9.

75. Kanehisa M, Goto S, Kawashima S, Okuno Y, Hattori M. The KEGG resource for deciphering the genome. Nucleic Acids Res Italic. 2004;32(Database issue):D277-80.

76. Ashburner M, Ball CA, Blake JA, Botstein D, Butler H, Cherry JM, Davis AP, Dolinski K, Dwight SS, Eppig JT, et al. Gene ontology: tool for the unification of biology. Nat Genet Italic. 2000;25(1):25-9.

\section{Ready to submit your research? Choose BMC and benefit from:}

- fast, convenient online submission

- thorough peer review by experienced researchers in your field

- rapid publication on acceptance

- support for research data, including large and complex data types

- gold Open Access which fosters wider collaboration and increased citations

- maximum visibility for your research: over $100 \mathrm{M}$ website views per year

At BMC, research is always in progress.

Learn more biomedcentral.com/submissions 